\title{
HTS Dipole Insert Developments
}

\author{
J.-M. Rey, M. Devaux, F. Bertinelli, X. Chaud, F. Debray, M. Durante, G. Favre, P. Fazilleau, T. Lécrevisse, \\ C. Mayri, C. Pes, F. Pottier, M. Sorbi, A. Stenvall, P. Tixador, J.-M. Tudela, T. Tardy, and G. Volpini
}

\begin{abstract}
Future accelerator magnets will need to reach a magnetic field in the $20 \mathrm{~T}$ range. Reaching such a magnetic field is a challenge only reachable using high temperature superconductor (HTS) material. The high current densities and stress levels needed to satisfy the design criterion of such magnets make $\mathrm{YBaCuO}$ superconductor the most appropriate candidate especially when produced using the IBAD route. The HFM EUCARD program is aimed at designing and manufacturing a dipole insert made of HTS material generating $6 \mathrm{~T}$ inside a $\mathrm{Nb}_{3} \mathrm{Sn}$ dipole of $13 \mathrm{~T}$ at 4.2 K. In the HTS insert, engineering current densities higher than $250 \mathrm{MA} / \mathrm{m}^{2}$ under $19 \mathrm{~T}$ are required to reach the performances. The stress level is consequently very high. The insert protection is also a critical issue as HTS shows low quench propagation velocity. The coupling with the $\mathrm{Nb}_{3} \mathrm{Sn}$ dipole makes the problem even more difficult. The magnetic and mechanical designs of the HTS insert will be presented as well as the technological developments underway to realize this compact dipole insert.
\end{abstract}

Index Terms-High field magnet, high temperature superconductor, YBaCuO.

\section{INTRODUCTION}

$\mathbf{E}$ UCARD PROGRAM has as primary goal to develop instruments and technologies for future accelerators [1]. High temperature superconductors (HTS) like $\mathrm{YBaCuO}$ (YBCO) are a non-negligible option for the magnets of future accelerators [2]. It permits to reach the very high field required thanks to their outstanding in field current capacities. In order to produce these kinds of magnets, the orientation of the field with respect to the HTS tape should be studied with caution [3], innovative protection scheme is needed [4], [5] and some technological developments are needed to withstand the high stress level. The objective of the study is to build a HTS magnet

Manuscript received October 22, 2012; accepted December 20, 2012. Date of publication January 4, 2013; date of current version January 23, 2013. This work was supported by the European Commission under the FP7 Research Infrastructures project EuCARD, Grant agreement 227579. This work is part of EuCARD Work Package 7: Super-conducting High Field Magnets for higher luminosities and energies.

J.-M. Rey, M. Devaux, M. Durante, P. Fazilleau, T. Lécrevisse, C. Mayri, C. Pes, and F. Pottier are with the CEA-DSM-IRFU-SACM, 91191 Gif sur Yvette cedx, France (e-mail: j-m.rey@ cea.fr).

F. Bertinelli, G. Favre and T. Tardy are with CERN, 1217 Meyrin, Switzerland.

X. Chaud, F. Debray, and J.-M. Tudela are with the Laboratoire National des Champs Magnétiques Intenses, LNCMI, CNRS/UJF/INSA/UPS 38042 Grenoble, France.

M. Sorbi and G. Volpini are with INFN Sezione di Milano LASA, 20090 Segrate, Milano, Italy.

A. Stenvall is with the Electromagnetics, Tampere University of Technology, 33101 Tampere, Finland.

P. Tixador is with the G2Elab/Institut Néel, CNRS/Grenoble-INP/UJF, 38042 Grenoble, France.

Color versions of one or more of the figures in this paper are available online at http://ieeexplore.ieee.org.

Digital Object Identifier 10.1109/TASC.2013.2237931
TABLE I

MAGNET CHARACTERISTICS

\begin{tabular}{lcc}
\hline \hline $\begin{array}{c}\text { Coil number } \\
\text { and Location }\end{array}$ & $\begin{array}{c}\text { Number of } \\
\text { turns }\end{array}$ & $\begin{array}{c}\text { Length (mm), } \\
\text { heads included }\end{array}$ \\
\hline 1-1' mid plane & 73 & 700 \\
2-2' medium & 61 & 350 \\
3-3' external & 35 & 326 \\
\hline \hline
\end{tabular}

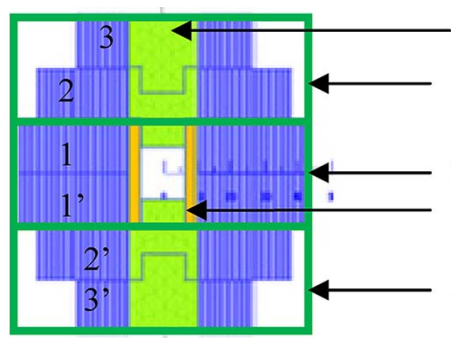

Iron post

$1^{\text {st }}$ double pancake

$2^{\text {nd }}$ double pancake

Compression plate

$3^{\text {rd }}$ double pancake

Fig. 1. Structure of the insert in 2D: three double-pancakes, iron post, and compression plates.

producing $6 \mathrm{~T}$ in an aperture of $99 \mathrm{~mm}$ inserted in a $\mathrm{Nb}_{3} \mathrm{Sn}$ dipole of $13 \mathrm{~T}$ [6]. The design and the realization of this insert are mainly driven by the control of the stresses in all parts of the magnet. The magnetic aspect only considers a central field of $6 \mathrm{~T}$, the field quality is not taken into account for this first magnet.

\section{InSERT MAGNet CONFIGURATION}

\section{A. Configuration and Geometry}

The outsert in $\mathrm{Nb}_{3} \mathrm{Sn}$ imposes some constrains on the HTS insert presented in [7]. The block type configuration suits very well the $\mathrm{YBaCuO}$ tape geometry, both for the winding and the magnetic field orientation mainly in the favorable longitudinal direction [7], [8].

Taking in to account the $99 \mathrm{~mm}$ external diameter, the $10 \mathrm{~mm}$ internal radius and the $12 \mathrm{~mm}$ height of the pancake (tape width), the insert consists of 6 coils: one central doublepancake of 73 turns and two external double-pancakes. The external double-pancake has 61 turns on the first coil and 35 turns on the second one (Table I and Fig. 1).

The insert is studied to be located in the straight section of the $\mathrm{Nb}_{3} \mathrm{Sn}$ outsert. That is why the central double-pancakes have the same length of the straight part of the outsert: $700 \mathrm{~mm}$. It is longer than the external double-pancakes in order to reduce the peak field problems at the edges. Layer jumps are installed in the straight parts of the pancakes, each of the twinned conductors having his layer jump in one straight length. Therefore 
TABLE II

INFLUENCE OF THE IRON POST

\begin{tabular}{cccccc}
\hline \hline & $\begin{array}{c}\text { B0 } \\
(\mathbf{T})\end{array}$ & $\begin{array}{c}\mathbf{B}_{\text {peak }} \\
(\mathbf{T})\end{array}$ & $\begin{array}{c}\mathbf{B}_{\text {peak }} \\
\text { heads } \\
(\mathbf{T})\end{array}$ & $\begin{array}{c}\mathbf{B}_{\perp_{\text {peak }} \text { straight }} \\
\text { section (T)/B } \\
\text { at this place }\end{array}$ & $\begin{array}{c}\mathbf{B} \perp_{\text {peak }} \\
\text { heads (T)/B } \\
\text { at this place }\end{array}$ \\
\hline $\begin{array}{l}\text { No post } \\
\text { Post }\end{array}$ & 5.5 & 6 & 6 & $2.5 / 3.11$ & $2.05 / 3.15$ \\
\hline \hline
\end{tabular}

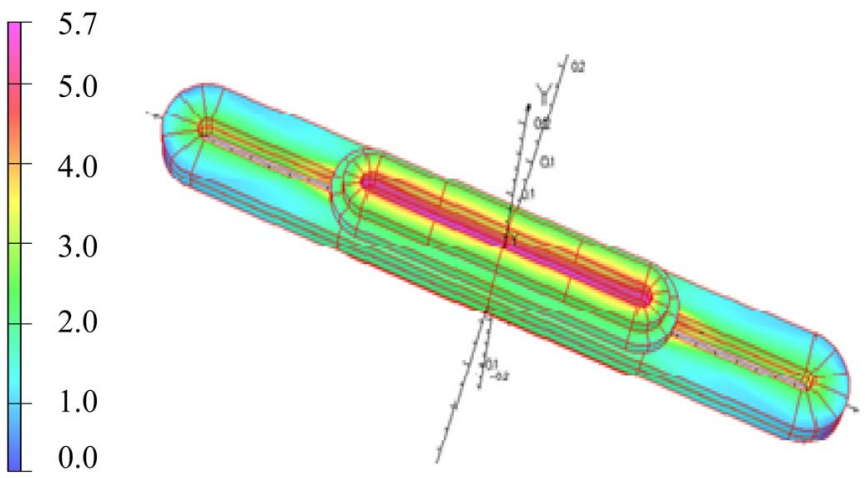

$\mathrm{B}(\mathrm{T})$

Fig. 2. Magnetic field in the insert.

the number of turns per pancake is odd despite the fact that the conductor is twinned (Table I).

\section{B. Influence of the Iron Post}

An iron post (Fig. 1) is placed in the center of the coils to improve the main field. Table II shows clearly the contribution of $10 \%$ of the post on the main field. The peak field is quite the same with or without the iron yoke. Its influence is studied carefully, especially the perpendicular field [6], [7] with a current density of $250 \mathrm{~A} / \mathrm{mm}^{2}$ : maximal perpendicular field is studied on the straight section and on the heads without or with iron and evaluated to the field at this place. We see that without post, $B \perp \max$ in the straight section represents $80 \%$ of the field without iron and $84 \%$ with iron. In the heads, $B \perp \max$ represents only $48 \%$ of the field in the case with iron, against $65 \%$ in the case with iron. Hence we see the benefit of the iron in the heads. Influence of the perpendicular field on the current density is presented next paragraph.

\section{Magnetic Field}

As mentioned in Table II and Fig. 2, the insert has a central field of $6.1 \mathrm{~T}$ and a peak field of $5.9 \mathrm{~T}$ located on the first turn of the first block in the middle of the straight section. The inductance is $4 \mathrm{mH}$ and the stored energy equals $16 \mathrm{~kJ}$ for a current density of $250 \mathrm{MA} / \mathrm{m}^{2}$.

Influence of the perpendicular field on the current density has been detailed clearly in [7]: $J c$ versus $B$ was plotted in the different critical points (Bmax and $B \perp \max$ in the straight section and the heads) for a $19 \mathrm{~T}$ background field. The most critical location was found to be in the straight section of coil 3 . Locally due to the field orientation, the critical current is reduced to around $3550 \mathrm{~A}$ for an operating current of $2800 \mathrm{~A}$ : the margin in current is thus around $27 \%$. By comparison where

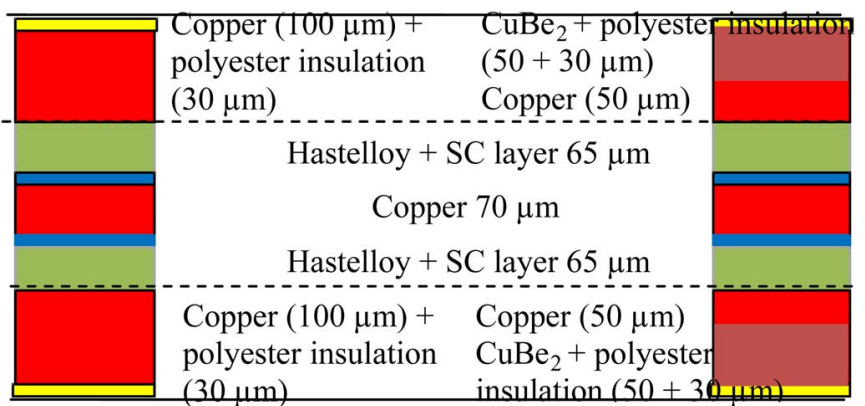

Fig. 3. Schematic cross-section of the conductor (a) with $\mathrm{Cu}$ alone or (b) with $\mathrm{CuBe}_{2}$. In yellow the polyester insulation (30 $\mu \mathrm{m}$ in each case), in red, the copper, in purple the $\mathrm{CuBe} 2$, in brown the hastelloy, and in blue the superconductor. The dotted line indicates a contact between the three tapes.

there is no perpendicular field the margin is around $70 \%$. It should be noted that this location is at the edge of a tape and that the opposite tape edge shows a far lower perpendicular field component, therefore the margin over the whole tape is greater than the calculated $27 \%$.

\section{COnductor Definition}

\section{A. Structure of the Conductor}

The conductor has been thought to fulfill several requirements:

- High current capacity

- Flexibility in the winding

- $\mathrm{YBaCuO}$ layer close to the neutral axis to limit stress in the coil ends

- Low resistance connections

- Mechanical resistance over $400 \mathrm{MPa}$

The conductor for the insert is made by assembling two tapes. The two $\mathrm{YBaCuO}$ layers are not transposed and behave like a thick superconducting layer. The two tapes are soldered together face to face (closest $\mathrm{YBaCuO}$ layers) through a $\mathrm{Cu}$ tape of the same thickness for the connection. The soldering eases the current redistribution between the two tapes. The tape thickness is about $65 \mu \mathrm{m}$ taking into account the $\mathrm{Cu}$ deposition above the Ag shunt for the soldering and a substrate of $50 \mu \mathrm{m}$. Two complementary copper tapes are placed in contact with the two YBCO tapes as shown on Fig. 3(a). The copper is required for electrical stabilization and to facilitate quench protection. These $\mathrm{Cu}$ tapes are not soldered to improve the flexibility of the conductor. Unfortunately pure copper tapes cannot hold the stress levels in the winding under 19 T. Reinforcement of the stabilizer is therefore required. The pure copper tape has been divided into two tapes, one of pure copper for its electrical properties and acting as a protection and one of $\mathrm{CuBe}_{2}$ alloy for its mechanical properties close to the hastelloy substrate [9] and acting as a reinforcement [Fig. 3(b)].

In order to increase the operating current and reduce the time constant to dump the stored energy, the conductor is co-wound in pairs.

\section{B. Characterization of $\mathrm{CuBe}_{2}$}

Different experiments have been done to determine the resistivity and mechanical properties of $\mathrm{CuBe}_{2}$ (ultimate stress, 
TABLE III

RESISTIVITY OF $\mathrm{CuBe}_{2}$

\begin{tabular}{ccc}
\hline \hline & $\begin{array}{c}\text { Resistivity at } \\
\mathbf{7 7} \mathbf{~ K}\end{array}$ & $\begin{array}{c}\text { Resistivity at } \\
\mathbf{3 0 0} \mathbf{~ K}\end{array}$ \\
\hline $\mathrm{CuBe}_{2}$ & $6.9 .10^{-8}$ & $8.7 .10^{8}$ \\
AnnealedCuBe $_{2}$ & $5.4 .10^{-8}$ & $6.8 .10^{-8}$ \\
\hline \hline
\end{tabular}

TABLE IV

Tensile Tests ON CuBe 2 (77 And $300 \mathrm{~K}$ )

\begin{tabular}{cccc}
\hline \hline & $\begin{array}{c}\text { Ultimate } \\
\text { stress (MPa) }\end{array}$ & $\begin{array}{c}\text { Elastic stress } \\
\text { (MPa) }\end{array}$ & $\begin{array}{c}\text { Maximal } \\
\text { elongation (\%) }\end{array}$ \\
\hline $\mathrm{CuBe}_{2}(77 \mathrm{~K})$ & 910 & 750 & 30 \\
Annealed $\mathrm{CuBe}_{2}(77 \mathrm{~K})$ & 1530 & 1280 & 7 \\
$\mathrm{CuBe}_{2}(300 \mathrm{~K})$ & 685 & 570 & 16 \\
Annealed $\mathrm{CuBe}_{2}(300 \mathrm{~K})$ & 1250 & 950 & 3 \\
\hline \hline
\end{tabular}

elastic stress and maximal elongation) at $77 \mathrm{~K}$ and $300 \mathrm{~K}$. Measurements were done with two different $\mathrm{CuBe}_{2}$ tapes of $12 \mathrm{~mm}$ wide and $135 \mu \mathrm{m}$ thickness: some have been annealed at $300^{\circ} \mathrm{C}$ during 3 hours contrary to the other ones. Table III shows the results of the resistivity of $\mathrm{CuBe}_{2}$.(Table IV)

Tensile tests have been done thanks to Instron Calibration Lab $5500 \mathrm{R}$. The samples are fixed between two pads from a distance of $70 \mathrm{~mm}$. The velocity of the stretching is $4 \mathrm{~mm} / \mathrm{s}$.

$\mathrm{CuBe}_{2}$, annealed or not, confirms the good mechanical resistance of this material at $77 \mathrm{~K}$. Protection calculations are underway to definitively choose one of the conductor or a solution between the two conductors: a compromise should be done as we will need $\mathrm{CuBe}_{2}$ for mechanical reasons and $\mathrm{Cu}$ for protection.

\section{Electrical Insulation of the Conductor}

The turn to turn electrical insulation is a polyester tape of $30 \mu \mathrm{m}$ applied on the external face of the $\mathrm{CuBe}_{2}$. A ground and inter-pancake of $0.2 \mathrm{~mm}$ made of G10 foils is added between each coils to insulate them between them.

\section{Protection}

Protection of this insert and what happens in case of quench of the insert or the outsert is presented by E. Häro [5].

\section{Mechanical Structure}

A preliminary magnetic design has been defined to determine forces in the structure. The configuration chosen is the worst case scenario i.e. with the $\mathrm{Nb}_{3} \mathrm{Sn}$ field contribution of $13 \mathrm{~T}$ under a total field of $19 \mathrm{~T}$. In this configuration, the maximum deformation must be inferior to $0.5 \mathrm{~mm}$ : the insert should transfer no load on the $\mathrm{Nb}_{3} \mathrm{Sn}$ dipole. After evaluating forces on the blocks of the insert, we defined the structure and materials to support them and then we reorganized the coils position.

The structure presented in Fig. 4 is designed to maintain resulting forces on half of the coils equal to $7.36 \mathrm{MN} / \mathrm{m}$ in

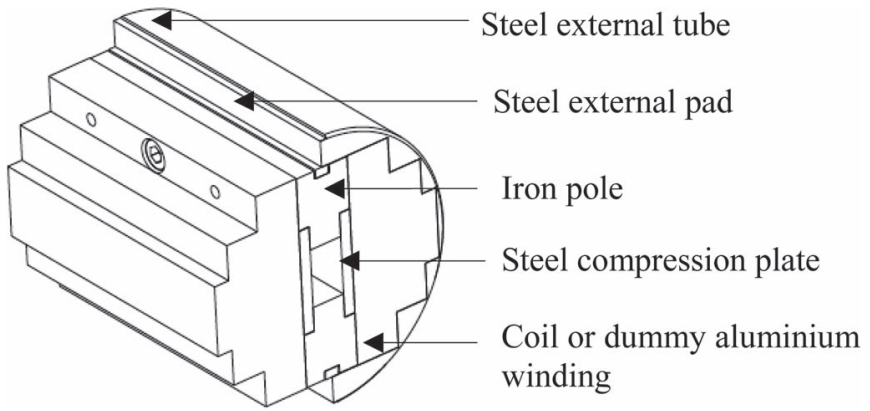

Fig. 4. Mechanical structure of the insert.

the horizontal direction and null on the vertical direction in the straight section. Forces on the heads are negligible compared to forces in the straight section. Von Mises stresses on the coils are evaluated to around $300 \mathrm{MPa}$ with some peak stress at $400 \mathrm{MPa}$. Conductors with $\mathrm{CuBe}_{2}$ are considered to support stresses up to $500 \mathrm{MPa}$ and those with only $\mathrm{Cu}$ only $300 \mathrm{MPa}$. These results confirm the relevancy of adding $\mathrm{CuBe}_{2}$ in conductors.

To maintain forces and to not load them on the $\mathrm{Nb}_{3} \mathrm{Sn}$ dipole, no impregnation is envisaged on the coils due to the possible delamination of the conductors [11]. An efficient system of pads and tube is planned with the following purpose for each component:

- External pad: it is used to apply uniformly the load from the coil winding to the external tube. The Von Mises stresses on the pad can be up to $800 \mathrm{MPa}$ on some critical points. The material used will probably be 304 stainless steel due to its high elastic limit [12].

- Compression plate: they reduce the oval shape induced by the magnetic loads by keeping the compression stiffness in the $\mathrm{Y}$ direction.

- Pole: they ensure the compression stiffness in the Y direction by applying load on the compression plates. The material is iron for its magnetic contribution

- External tube: it carries the resulting load and limits the deformation. Due to the magnetic forces it will become ovoid. The material will be Nitronic alloy high elastic limit. Its thickness is $3 \mathrm{~mm}$ optimized to have stresses around $500 \mathrm{MPa}$ [7].

\section{Assembly}

The conductor will be in three ribbons: one $\mathrm{Cu}+\mathrm{CuBe}_{2}$ insulated, one $\mathrm{SC}+\mathrm{Cu}+\mathrm{SC}$ and then one $\mathrm{Cu}+\mathrm{CuBe}_{2}$ insulated. As we will wind in pairs, six ribbons will be wound together and maintained by contact (winding tension are enough to maintain them). Mid-plane pancakes will be wound together around the compression plates. Other coils will be wound as double-pancake around the iron post (separated in 2 parts, see Fig. 1) and piled on the first coils.

Then pads of $100 \mathrm{~mm}$ will be fitted in staggered rows of $50 \mathrm{~mm}$ all along the coils. They will be cut by electro erosion at LNCMI-Grenoble. A first test has been done successfully as presented in Fig. 5. Then they will be electron beam welded. Preliminary welding trials are underway at Cern.

The external tube will be assembled in 8 parts of $100 \mathrm{~mm}$ on the external pads. As the internal radius of the tube $(93 \mathrm{~mm})$ 


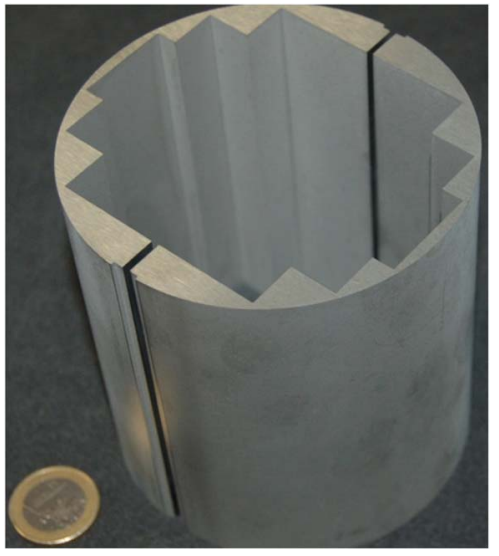

Fig. 5. First test of electro-erosion of a pad of $100 \mathrm{~mm}$.

equals the external tube of the pads, we are currently study the assembly of the tube on the pads by thermal shrinkage. The solution plans to heat the tube with temperature over $500 \mathrm{~K}$ and to slide it over the pad. Moreover, the tube in seven parts is easier to assemble than a longer one.

The tube is then half-recovered with kapton to ensure the electric insulation between the insert and the $\mathrm{Nb}_{3} \mathrm{Sn}$ dipole.

A mock up with a dummy aluminum winding is planned to validate all the steps of the presented assembly.

\section{CONCLUSION}

The design for the HTS insert is now well advanced. New developments have been realized and validated. A pancake prototype will be built and tested in different field directions to confirm models and influence of perpendicular fields. Using these results, the insert will be realized and tested in the dipole FRESCA II [6] to reach a central field of $19 \mathrm{~T}$ in the test station.

\section{ACKNOWLEDGMENT}

The authors thank R. Rabette from CNRS for his measurements and calculations on $\mathrm{CuBe}_{2}$ conductor. They thank also Prof. Y. Iwasa from MIT and G. de Rijk from CERN for fruitful discussions and constructive criticism.

\section{REFERENCES}

[1] EuCARD, European Coordination for Accelerator Research and Development. [Online]. Available: http://eucard.web.cern.ch/eucard/index.html

[2] Y. Iwasa, Case Studies in Superconducting Magnets, Design and Operational Issues, 2nd ed. Springer Science, 2009.

[3] X. Chaud, F. Debray, L. Ronayette, E. Mossang, P. Brosse-Maron, A.-J. Vialle, P. Tixador, J.-M. Rey, T. Lecrevisse, and C.-E. Bruzek, "A characterization of YBCO coated conductors under high magnetic field at LNCMI," IEEE Trans. Appl. Supercond., vol. 22, no. 3, p. 6600704 , 2012.

[4] A. Stenvall, M. Sorbi, G. Volpini, and R. Mikkonen, "Benchmark of two quench codes for the protection study of an high field HTS insert dipole," IEEE Trans. Appl. Supercond., vol. 21, no. 3, pp. 2458-246, 2011.

[5] E. Härö, A. Stenvall, T. Lecrevisse, J. Fleiter, J.-M. Rey, M. Sorbi, M. Devaux, C. Trophime, P. Fazilleau, G. Volpini, P. Tixador, F. Hornung, and C. Pes, "Quench considerations and protection scheme of high field HTS dipole insert coil," presented at the Conf. ASC, 2012.

[6] P. Ferracin, M. Devaux, M. Durante, P. Fazilleau, P. Fessia, P. Manil, A. Milanese, J. E. Munoz Garcia, L. Oberli, J. C. Perez, J. M. Rifflet, G. de Rijk, F. Rondeaux, and E. Todesco, "Development of the EuCARD $\mathrm{Nb}_{3}$ Sn dipole magnet FRESCA2," presented at the Conf. ASC, 2012.

[7] M. Devaux, F. Debray, J. Fleiter, P. Fazilleau, T. Lécrevisse, C. Pes, J. M. Rey, J. M. Rifflet, M. Sorbi, A. Stenvall, P. Tixador, and G. Volpini, "HTS insert magnet design study," IEEE Trans. Appl. Supercond., vol. 22, no. 3, p. $4203605,2012$.

[8] A. Xu, J. Jaroszynski, F. Kametani, Z. Chen, D. C. Larbalestier, Y. L. Viouchkov, Y. Chen, Y. Xie, and V. Selvamanickam, "Angular dependence of Jc for YBCO coated conductors at low temperature and very high magnetic fields," Sci. Technol., vol. 23, p. 014003, 2010.

[9] [Online]. Available: http://www.ngkbf.com

[10] N. M. Wilson, Superconducting Magnets. Oxford Science Publications, 1983.

[11] T. Takematsu, R. Hu, T. Takao, Y. Yanagisawa, H. Nakagome, D. Uglietti, T. Kiyoshi, M. Takahashi, and H. Maeda, "Degradation of the performance of a YBCO-coated conductor double pancake coil due to epoxy impregnation," Phys. C, vol. 470, pp. 674-677, 2010.

[12] R. P. Reed and A. F. Clark, Materials at Low Temperatures. ASM International, 1983. 